\title{
REGULATION OF CORONAVIRUS TRANSCRIPTION: VIRAL AND CELLULAR PROTEINS INTERACTING WITH TRANSCRIPTION-REGULATING SEQUENCES
}

\author{
Sonia Zúñiga, Isabel Sola, Jose L. Moreno, Sara Alonso, \\ and Luis Enjuanes*
}

\section{INTRODUCTION}

The last step in the current model of coronavirus transcription is a template switch during synthesis of the negative strand, to complete the minus sgRNA. ${ }^{1}$ It was shown that the free energy of duplex formation between leader transcription-regulating sequence (TRS-L) and the nascent negative-strand plays a crucial role in template switch and is the driving force of coronavirus transcription., ${ }^{2,3}$ This step requires overcoming an energy threshold. Coronavirus nucleoprotein $(\mathrm{N})$ plays a structural role in virus assembly and has also been shown to be important in RNA synthesis. ${ }^{4}$ In addition, template switching, an obligatory step in $\mathrm{CoV}$ transcription, needs to overcome an energy threshold. Therefore, we asked whether RNA chaperones are involved in transcription and, most importantly, if $\mathrm{N}$ is an RNA chaperone.

RNA chaperones are proteins that bind RNA with broad specificity and that rescue RNAs trapped in unproductive folding states..$^{5-8}$ One of their main characteristics is that, once the RNA has been folded, they are no longer needed and, therefore, they can be removed without altering RNA conformation. There are three RNA chaperone activities easily evaluable in vitro: (i) enhancement of RNA ribozyme cleavage, (ii) rapid and accurate RNA-RNA annealing, and (iii) facilitation of RNA strand transfer and exchange.

RNA chaperones decrease the activation energy required for a transition between two states, which is energetically favored. Template switch during coronavirus transcription could be interpreted as a transition between two states: in the first one, a duplex between the nascent minus RNA strand and the genomic positive RNA used as template is formed; in the second one, the nascent RNA strand is paired with the TRS of the leader. Therefore, RNA chaperones could be involved in template switch by decreasing the energy required for the transition from the first to the second duplex (Fig. 1).

\footnotetext{
* Centro Nacional de Biotecnología, CSIC, Darwin, 3, Cantoblanco, 28049, Madrid, Spain.
} 

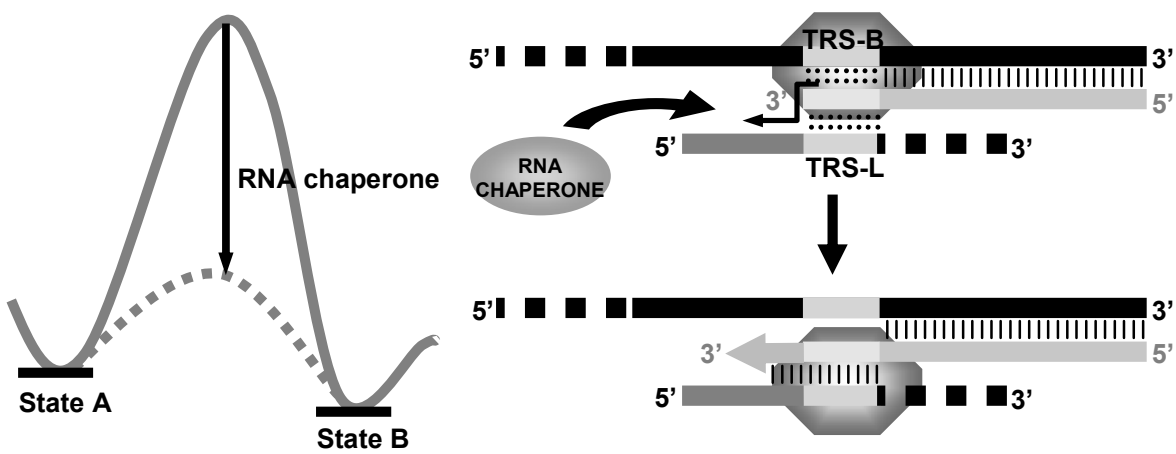

Figure 1. Tentative RNA chaperone involvement in template switch during coronavirus transcription. Left panel, scheme illustrates the action of RNA chaperones. Right panel, elements involved in the template switch step of coronavirus transcription.

Up to now, there are just three RNA chaperones described and all are nucleocapsid proteins from three RNA viruses: (i) retrovirus, the best one analyzed being that of human immunodeficiency virus (HIV-1), 9,10 (ii) hepatitis delta virus (HDV), ${ }^{11,12}$ and (iii) hepatitis $\mathrm{C}$ virus $(\mathrm{HCV}) .{ }^{13}$ We thought that coronavirus $\mathrm{N}$ proteins are good candidates to be RNA chaperones. We used transmissible gastroenteritis virus (TGEV) as a model to investigate this possibility. No RNA chaperone activity can be predicted based on domain conservation. Nevertheless, it was recently reported that RNA chaperones are the protein class with the highest frequency of containing long intrinsically disordered regions. ${ }^{14}$ Structural analyses of coronavirus $\mathrm{N}$ proteins showed that they also fulfill this criterion.

\section{MATERIALS AND METHODS}

\subsection{Protein Expression and Purification}

TGEV N gene, nucleotides 26917 to 28065 from the genome (GeneBank accession number AJ271965), was cloned into the pGEX-4T-2 vector (Amersham Biosciences). Plasmid pET28a-PTB ${ }^{15}$ was a generous gift from D. Black (Howard Hughes Medical Institute, UCLA). Escherichia coli cells, strain BL21(DE3)pLys (Novagen), were transformed with plasmids pGEX4T2-N or pET28a-PTB. GST-N fusion protein was purified using Glutathione Sepharose 4B (Amersham Biosciences) according to the manufacturer's specifications. His-PTB protein was purified as previously described. ${ }^{15}$

\subsection{Electrophoretic Mobility Shift Assay (EMSA)}

RNA-protein binding reactions were performed by incubating 10 or 1 pmol of biotinylated RNA with $300 \mathrm{ng}$ of recombinant purified protein in binding buffer $(12 \%$ glycerol, $20 \mathrm{mM}$ TrisHCl pH 7.4, $50 \mathrm{mM} \mathrm{KCl,} 1 \mathrm{mM}$ EDTA, $1 \mathrm{mM} \mathrm{MgCl} 2,1 \mathrm{mM}$ DTT) for $30 \mathrm{~min}$ at $25^{\circ} \mathrm{C}$. Reactions were loaded on a $4 \%$ non denaturing PAGE. After electrophoresis, the gel was blotted onto positively charged nylon membranes (BrightStar-Plus, 
Ambion) following the manufacturer's instructions. Detection of the biotinylated RNA was performed using the BrightStar BioDetect kit (Ambion). When indicated, recombinant protein was preincubated with $\mathrm{mAb} 30$ minutes at $4^{\circ} \mathrm{C}$.

\subsection{In Vitro Self-cleavage of RNA}

pBdASBVd[A28] ${ }^{16}$ was a generous gift from J.A. Daròs and R. Flores (Plant Molecular and Cell Biology Institute, UPV). In vitro transcription, cleavage, and electrophoresis of dimeric ASBVd (+) RNA was performed as previously described ${ }^{16}$ except that the RNA was labeled with biotin. Densitometric analysis of the bands from three different experiments was performed using Quantity One 4.5.1 Software (BioRad).

\section{RESULTS AND DISCUSSION}

The functionality of purified TGEV N protein on RNA binding was evaluated by EMSA. Recombinant N protein was incubated with biotinylated RNA oligonucleotides representing viral TRSs or a cellular RNA. A band shift appeared in all cases, indicating that $\mathrm{N}$ protein binds RNA nonspecifically, as expected (data not shown). To map the RNA binding domain in the $\mathrm{N}$ protein, a set of monoclonal antibodies (mAbs), generated in our laboratory, was used. ${ }^{17}$ In similar EMSA experiments, it was found that some of the mAbs recognizing the amino terminus of the protein significantly blocked N-RNA binding, while mAbs recognizing the carboxy terminus did not, and a supershift band appeared in these cases (data not shown). A mAb from each set was used in subsequent experiments.
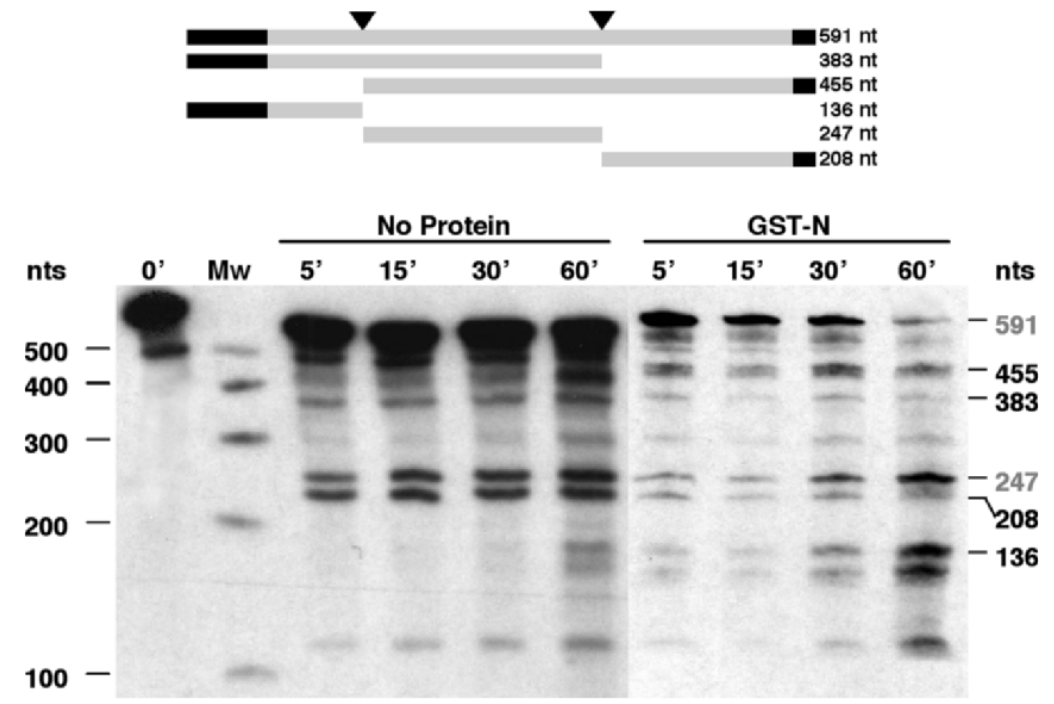

Figure 2. Hammerhead ribozyme self-cleavage. Upper panel, scheme of the substrate (591 nt) and the selfprocessed products. Low panel, time-course in cleavage conditions. 


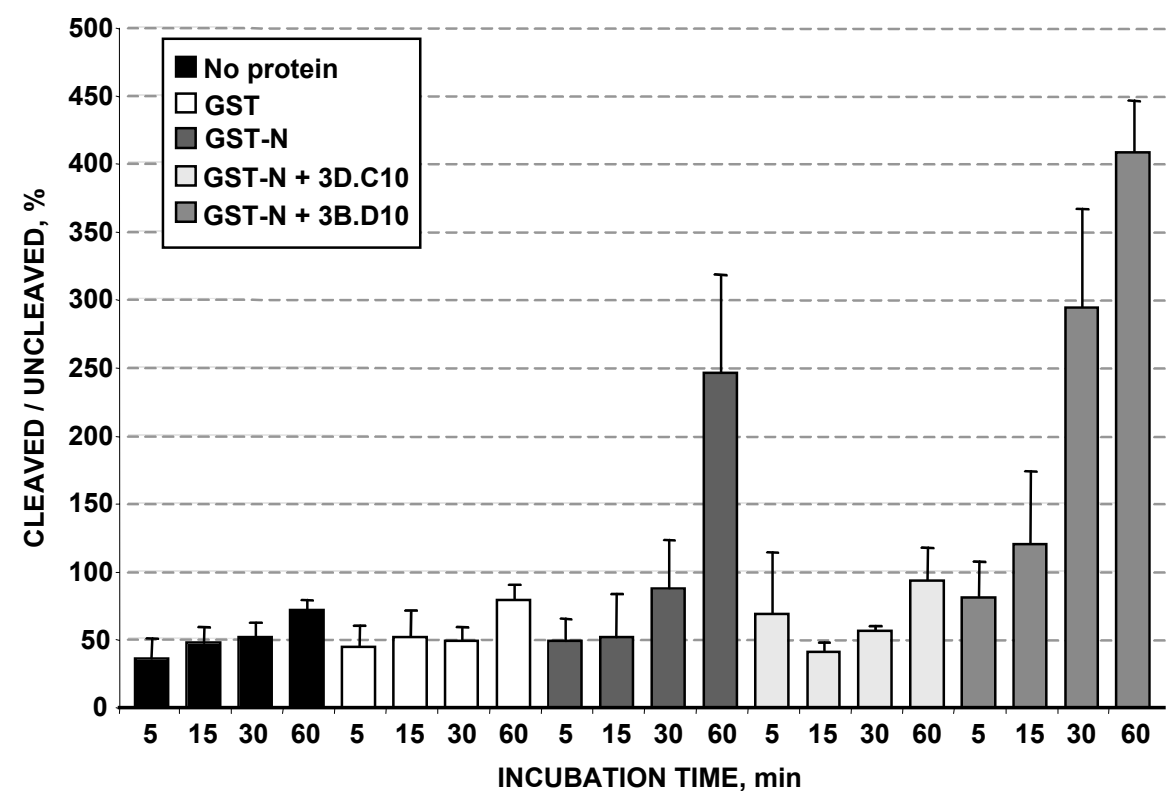

Figure 3. Recombinant TGEV N protein enhances ribozyme self-cleavage. Densitometric quantification of time-course of ribozyme self-cleavage reactions. Error bars indicate the standard deviation from three independent experiments.

Once the functionality of the recombinant $\mathrm{N}$ protein was assessed, an advanced RNA chaperone assay was performed. Avocado sunblotch viroid (ASBVd) dimer RNA was used in a hammerhead ribozyme self-cleavage assay. ${ }^{16}$ This RNA has two ribozyme cleavage sites and must be properly folded for the cleavage reaction to take place. In the absence of protein, under cleavage conditions, all processed products appeared but there was no progression in the cleavage reaction with incubation time. In contrast, in the presence of recombinant $\mathrm{N}$ protein, cleavage products appeared, with a significant decrease in the amount of uncleaved products (Fig. 2). This result strongly suggested that TGEV N protein is an RNA chaperone.

Similar experiments were performed with several controls, and the bands corresponding to the uncleaved substrate and the completely cleaved product were quantified (Fig 3). In the absence of protein, there were no changes in the cleavage reaction with incubation time. The same result was obtained in the presence of the control GST protein. In the presence of recombinant $\mathrm{N}$ protein, the ratio of cleaved to uncleaved product increased more than threefold compared with reactions lacking the $\mathrm{N}$ protein. This enhancement of the cleavage reaction was due to the $\mathrm{N}$ protein, because preincubation of the GST-N with a mAb that blocked RNA-protein binding also blocked activity in the cleavage reaction. The levels of cleavage product obtained were similar to those observed in the absence of $\mathrm{N}$ protein. Similarly, $\mathrm{N}$ protein preincubated with a $\mathrm{mAb}$ that did not block N-RNA binding enhanced the cleavage reaction, and the ratio of cleaved to uncleaved product was more than fivefold compared with the protein-free reactions. The 
difference between results obtained with GST-N protein alone or with the mAb present was probably explained by an aggregation effect. The enhancement produced by the $\mathrm{N}$ protein was not simply due to its RNA binding ability, as another RNA binding protein, polypyrimidine tract binding protein (PTB), did not exert any effect on the cleavage reaction (data not shown). These results clearly indicate that TGEV N protein is a RNA chaperone.

However, this is a heterologous system and therefore, preliminary annealing experiments were performed using a biotinylated TRS-L and a unlabeled cTRS-7. In the presence of $\mathrm{N}$ protein, at $25^{\circ} \mathrm{C}$ or $37^{\circ} \mathrm{C}$, the amount of dsRNA was higher than that obtained from protein-free reactions, as confirmed by quantifying the gel bands (data not shown). Even in the presence of magnesium, which stabilizes dsRNAs, the effect of $\mathrm{N}$ protein was still noted and confirmed by quantification of gel bands. These results strongly suggest that the CoV N protein promotes the annealing of viral TRSs.

The next step will be to study the role of this RNA chaperone activity in vivo, in coronavirus transcription.

\section{REFERENCES}

1. S. G. Sawicki and D. L. Sawicki, A new model for coronavirus transcription, Adv. Exp. Med. Biol. 440, 215-220 (1998).

2. I. Sola, J. L. Moreno, S. Zúñiga, S. Alonso, and L. Enjuanes, Role of nucleotides immediately flanking the transcription-regulating sequence core in coronavirus subgenomic mRNA synthesis, J. Virol. 79, 2506$2516(2005)$

3. S. Zúñiga, I. Sola, S. Alonso, and L. Enjuanes, Sequence motifs involved in the regulation of discontinuous coronavirus subgenomic RNA synthesis, J. Virol. 78, 980-994 (2004).

4. F. Almazán, C. Galán, and L. Enjuanes, The nucleoprotein is required for efficient coronavirus genome replication, J. Virol. 78, 12683-12688 (2004).

5. G. Cristofari and J. L. Darlix, The ubiquitous nature of RNA chaperone proteins, Prog. Nucleic Acid Res. Mol. Biol. 72, 223-268 (2002).

6. D. Herschlag, RNA chaperones and the RNA folding problem, J. Biol. Chem. 270, 20871-2084 (1995).

7. J. R. Lorsch, RNA chaperones exist and DEAD box proteins get a life, Cell 109, 797-800 (2002).

8. R. Schroeder, A. Barta, and K. Semrad, Strategies for RNA folding and assembly, Nat. Rev. Mol. Cell. Biol. 5, 908-919 (2004).

9. E. L. Bertrand and J. J. Rossi, Facilitation of hammerhead ribozyme catalysis by the nucleocapsid protein of HIV-1 and the heterogeneous nuclear ribonucleoprotein A1, EMBO. J. 13, 2904-2912 (1994).

10. Z. Tsuchihashi and P. O. Brown, DNA strand exchange and selective DNA annealing promoted by the Human Immunodeficiency Virus Type I nucleocapsid protein, J. Virol. 68, 5863-5870 (1994).

11. Z. S. Huang and H. N. Wu, Identification and characterization of the RNA chaperone activity of hepatitis delta antigen peptides, J. Biol. Chem. 273, 26455-26461 (1998).

12. Z. S. Huang, W. H. Su, J. L. Wang, and H. N. Wu, Selective strand annealing and selective strand exchange promoted by the N-terminal domain of hepatitis delta antigen, J. Biol. Chem. 278, 5685-5693 (2003).

13. G. Cristofari, R. Ivanyi-Nagy, C. Gabus, et al., The hepatitis $\mathrm{C}$ virus Core protein is a potent nucleic acid chaperone that directs dimerization of the viral (+) strand RNA in vitro, Nucleic Acids Res. 32, 2623-2631 (2004).

14. R. Ivanyi-Nagy, L. Davidovic, E. W. Khandjian, and J. L. Darlix, Disordered RNA chaperone proteins: from functions to disease, Cell. Mol. Life Sci. 62, 1409-1417 (2005).

15. J. Xie, J. Lee, T. L. Kress, K. L. Mowry, and D. L. Black, Protein kinase A phosphorylation modulates transport of the polypyrimidine tract-binding protein, Proc. Natl. Acad. Sci. USA 100, 8776-8781 (2003).

16. J. A. Daròs and R. Flores, A chloroplast protein binds a viroid RNA in vivo and facilitates its hammerheadmediated self-cleavage, EMBO. J. 21, 749-759 (2002).

17. J. M. Martín-Alonso, M. Balbín, D. J. Garwes, L. Enjuanes, S. Gascón, and F. Parra, Antigenic structure of transmissible gastroenteritis virus nucleoprotein, Virology 188, 168-174 (1992). 